\title{
Environmental Education: Pedagogical Practices of Awareness in Combating and Reducing Burned Indices
}

\section{Greyce dos Santos Rodrigues', Claudio Alves Nahum², David do Socorro Barros Brasil ${ }^{3}$, Tereza Rodrigues Felipe ${ }^{4}$, Vanise dos Santos Rodrigues ${ }^{5}$, Philip Floriano Rodrigues Ramkeerat ${ }^{6}$}

\author{
1,2,4,5,6 Universidade Federal do Pará-UFPA - Belém/PA - Brasil. \\ ${ }^{4}$ Instituto de Tecnologia de Educação Galileo da Amazônia (ITEGAM). Manaus-Amaznas-Brasil. \\ Email:greyce.gsr@gmail.com,nahum@ufpa.br,dsbbrasil@ig.com.br,tereza_itegam10@hotmail.com, \\ vanise_santosrodrigues@hotmail.com, philip_ramkeerat@hotmail.com
}

Received: March $23^{\text {th }}, 2017$

Accepted: April $17^{\text {th }}, 2017$

Published: June $30^{\text {th }}, 2017$

Copyright (02016 by authors and Institute of Technology Galileo of Amazon (ITEGAM). This work is licensed under the Creative Commons Attribution International License (CC BY 4.0).

http://creativecommons.org/lic enses/by/4.0/

\begin{abstract}
This research presents a case study that was carried out in a municipal school located in the East Zone of the Municipality of Manaus. The project was developed in two classes of elementary school I for a quantitative of 80 (eighty) students of both sexes with ages between 10 and 13 years belonging to the 5 th year of elementary school I aiming to propose a reflection on formal and non-formal environmental education. -formal approach to pedagogical practices regarding awareness, awareness and conservation for the development of environmental social transformation in the school context. Among the environmental education practices developed in this school are: lectures on fighting and control of fires, prevention of epidemiology and pollution of the environment. After the lectures the students expressed the learning of environmental perception through a workshop to create drawings that were exposed to the school community. These drawings and the learning with the lectures motivated the students to fight the destruction of the environment. For this, posters were prepared by the students to be used in a mobilizing walk of awareness about the conservation and preservation of the environment. In this walk were distributed seedlings to be planted next to the community located in the middle of the school.school for a quantitative of 80 (eighty) students of both sexes, aged 10 to 13 years, belonging to the 5th year Of elementary school I.
\end{abstract}

Keywords: Environmental Education. Environmental Perception. Pedagogical practices.

\section{RESUMO}

\section{Educação Ambiental: Práticas Pedagógicas de Conscientização no Combate e Redução dos Índices de Queimadas}

A presente pesquisa apresenta um estudo de caso que foi realizado em uma escola Municipal localizado na Zona Leste do Município de Manaus. O projeto foi desenvolvido em duas turmas do ensino fundamental I para um quantitativo de 80 (oitenta) alunos de ambos os sexos com idade entre 10 e 13 anos pertencentes ao $5^{\circ}$ ano do ensino fundamental I visando propor uma reflexão sobre a Educação ambiental formal e não-formal voltada às práticas pedagógicas no que concerne a sensibilização, conscientização e conservação para o desenvolvimento da transformação social ambiental no contexto escolar. Dentre as práticas de educação ambiental desenvolvidas nessa escola citam-se: a realização de palestras sobre combate e controle de queimadas, prevenção de epidemiologias e poluição do meio ambiental. Após as palestras os alunos expressaram o aprendizado de percepção ambiental através de uma oficina de criação de desenhos os quais foram expostos para a comunidade escolar. Esses desenhos e o aprendizado com as palestras motivaram os alunos a combater a destruição do meio ambiente. Para isso, foram confeccionados pelo alunos cartazes para serem usados em uma caminhada mobilizadora de conscientização sobre a conservação e preservação do meio ambiente. Nessa caminhada foram distribuídos mudas para serem plantadas junto à comunidade localizada no entrono da escola.

Palavras Chaves: Educação Ambiental. Percepção Ambiental. Práticas Pedagógicas.

\section{INTRODUÇÃO}

Esse estudo vemcontribuir de forma significativa sobre as práticas pedagógicas de ensino voltado para ao meio ambiente. Onde apresentará uma pesquisa que será realizada em uma escola Municipal localizado na Zona Leste de Manaus objetivando propor uma reflexão interdisciplinar sobre a percepção da educação ambiental no ensino fundamental I voltada às práticas pedagógicas no que concerne a sensibilização, conscientização e conservação para o desenvolvimento da transformação social ambiental.

A problemática ambiental é de cunho social e principalmente educacional e vem superando os âmbitos dos 
saberes e dos sistemas de conhecimento constituídos permitindo compreender as ações e suas consequências produzidas no contexto social, pelo homem e principalmente no que concerne ao meio ambiente.

Desenvolver nos alunos de modo formal e não-formal o senso crítico quanto a conservação para o cuidado coms eu próprio meio no qual está inserido e que possam compreender a necessidade da sustentabilidade e como conservar o meio ambiente partindo deste pressuposto. Serão desenvolvidas atividades envolvendo as práticas pedagógicas interdisciplinando com a educação ambiental com a finalidade de preservar e conservar o meio ambiente, que consequentemente a reflexão de forma positiv a a vida do homem voltada a sensibilização, consciência e conservação ambiental para o desenvolvimento da transformação social ambiental

Considerando que o meio ambiente é fundamental para continuidade da espécie humana, a ins erção da conscientização nas escolas ou em seu cotidiano familiar deve impactar a atividade humana em seu as pecto social. E como essa reflexão ambiental por meio da percepção vai minimizar impactos no contexto ambiental através das práticas pedagógicas?

Diante deste contexto à Educação Ambiental alicerçada na Lei 9.795/99, em seu art. 2º estabelece que a Educação Ambiental, haja vista, estar presente, de modo formal articulada, em todos os níveis e modalidade do processo educativo, em caráter formal e não-formal.

A pesquis a trata da percepção de uma análise reflexiva nas práticas pedagógicas, relacionadas à educação ambiental formal e informal. De acordo com a política nacional de educação ambiental na lei 9795/99em seu Art. $1^{\circ}$ compreende-se por educação ambiental:

Educação ambiental são os processos por meio dos quais o indivíduo e a coletividade constroem valores sociais, conhecimentos, habilidades, atitudes e competências voltadas para a conservação do meio ambiente, bem de uso comum do povo, essencial à sadia qualidade de vida e sua sustentabilidade.

Busca-se interdisciplinar essa temática em questão, haja vista ser um componente curricular es sencial e permanente da base da educação nacional. Alicerçada na lei no 9795/99 que em seu art. 10 comenta que a educação ambiental é como uma prática educativa integradora, contínua e permanente em todos os níveis e modalidades do ensino formal. Visto que é através de práticas pedagógicas desenvolvidas efetivava-se a sensibilização, conscientização e principalmente a conservação o meio ambiente.

Atualmente, vive-se em um mundo, não preocupado em questões voltadas ao meio ambiente. É com essa finalidade que busca-se desenvolver a educação ambiental com os alunos e juntamente com a comunidade.

No que tange a Educação Ambiental Não-formal a lei $\mathrm{n}^{\circ}$ 9795/99 no art. 13, compreende que as ações e práticas educativas voltadas à sensibilização da coletividade sobre as questões ambientais e à sua organização e participação na defesa da qualidade do meio ambiente desta forma constroemconhecimentos e principalmente atitudes voltadas para sensibilização, conscientização e conservação do meio ambiente. Nesse contexto Educação Informal envolve todos os segmentos da população, dentre os quais se destacam os grupos de mulheres, de jovens, trabalhadores, políticos, empresários, associações de moradores, profissionais liberais, dentre outros.

Dentro desse contexto as práticas pedagógicas vem contribuir para a redução dos índices de queimadas, assim como também contribuir para as atividades voltadas para a conscientização, sensibilização, conservação e preservação do meio ambiente, através do trabalho pedagógico de cunho ambiental voltado aos alunos de modo formale não-forma fins de redução das atividades contra o meio ambiente ocasionado pelas queimadas.

O des matamento e as queimadas são considerados grandes problemas ecológicos enfrentados pelo país na atualidade, haja vista serem provenientes da agricultura, da criação bovina, da ocupação desordenada como, por exemplo, as invasões, de terras para construção de novas habitações

As queimadas na Amazônia acorrem principalmente no período do verão, onde o clima fica seco e propício à cultura da queima de floresta para efetuar a plantação em grande porte. Essa tendência de agricultura tem como objetivo o abastecimento da economia da capital do estado do Amazonas. Com isso os maiores prejudicados são as comunidades ao seu entorno que com o alto índice de fumaça desenvolvem doenças respiratórias e o comercio local não progride.

Outrossim, busca-se a contribuição pedagógica e a intervenção através das práticas pedagógicas ambientais para combater a cultura da queimada, principalmente na comunidade, incentivando a conservação do meio ambiente dando ênfase a prática pedagógica atuando de modo formal e não-formal. Para incentivar a cultura da conservação e preservação ambiental, humanitária não desperdiçando, os conhecimentos adquiridos exercendo corretamente sua cidadania.

\section{REVISÃO BIBLIOGRÁFICA}

\section{II.1 EDUCAÇÃO AMBIENTAL}

Educação Ambiental alicerçada na Lei 9.795/99, em seu art. $2^{\circ}$, estabelece que a Educação Ambiental, haja vista, estar presente, de modo formal- articulada, em todos os níveis e modalidades do processo educativo, em caráter formal e nãoformal.

De acordo com a Política Nacional de Educação Ambiental na Lei 9795/99 em seu Art. 1o compreende por educação ambiental por todos os processos por meio dos quais o indivíduo e a coletividade constroem valores sociais, conhecimentos, habilidades, atitudes e competências voltadas para a conservação do meio ambiente, bem de uso comum do povo, essencial à sadia qualidade de vida e sua sustentabilidade [1][2].

Estudos voltados para a temática de Educação Ambiental são focos de pesquisas nos últimos anos, tendo em vista que é um tema de grande importância. Dentre outros citam-se o estudo sobre as concepções e práticas do ensino de Educação Ambienta utilizadas por professores de ciência do Ensino Fundamental foi foco de pesquisa desenvolvido por [3].

Outrossim, compreende a educação ambiental aos processos nos quais o indivíduo e a coletividade constroem seus valores sociais, conhecimentos e competências voltadas para a conservação do meio ambiente.

A Educação Ambiental traz uma reflexão educativa, nu ma pers pectiva despertando nos alunos o interes se de conscientizaremse em relação ao meio ao qual está inserido através de práticas pedagógicas articulando a interdisciplinaridade utilizada solucionar a conscientização e conservação dentro do contexto ambiental diante de uma nova postura nas práticas pedagógica.

A educação ambiental é uma das ferramentas existentes para a sensibilização e capacitação da população em geral sobre os problemas ambientais. Com ela, busca-se desenvolver técnicas e métodos que facilitem o processo de tomada de consciência sobre 
a gravidade dos problemas ambientais e a necessidade urgente de nos debruçarmos seriamente sobre eles [4].

Nesse sentido cabe destacar que a educação ambiental assume cada vez mais uma função transformadora, na qual a coresponsabilização dos indivíduos torna-se um objetivo essencial para promover um novo tipo de desenvolvimento - o desenvolvimento sustentável. Entende-se, portanto, que a educação ambiental é condição necessária para modificar um quadro de crescente degradação socioambiental, mas ela ainda não é suficiente, o que, no dizer, se converte em "mais uma ferramenta de mediação necessária entre culturas, comportamentos diferenciados e interesses de grupos sociais para a construção das transformações desejadas". O educador tem a função de mediador na construção de referenciais ambientais e deve saber usá-los como instrumentos para o desenvolvimento de uma prática social centrada no conceito da natureza [5].

O Congresso de Belgrado, promovido pela UNESCO em 1975, definiu a Educação Ambiental (EA) como sendo um processo que visa [4]: “(...) formar uma população mundial consciente e preocupada como ambiente e com os problemas que he dizem respeito, uma população que tenha os conhecimentos, as competências, o estado de espírito, as motivações e o sentido de participação e engajamento que the permita trabalhar individualmente e coletivamente para resolver os problemas atuais e impedir que se repitam [...]".

No Capítulo 36 da Agenda 21, a Educação Ambiental tem em seu objetivo 2,3 e 4: 2. Desenvolver consciência do meio ambiente e desenvolvimento em todos os setores da sociedade em escala mundial e com a maior brevidade possível; 3. Lutar para facilitar o acesso à educação sobre meio ambiente $e$ desenvolvimento, vinculada à educação social, desde a idade escolar primaria até a idade adulta em todos os grupos da população; 4. Promover a integração de conceitos de ambiente e desenvolvimento, inclusive demografia, em todos os programas de ensino, em particular a análise das causas dos principais problemas ambientais e de desenvolvimento em contexto local, recorrendo para isso as melhores provas científicas disponíveis e a outras fontes apropriadas de conhecimentos, e dando especial atenção ao aperfeiçoamento do treinamento dos responsáveis por decisões em todos os níveis.

Nessa busca do processo de consciência da sociedade o meio ambiente encontra-se uma problemática para de resolução com maior brevidade, haja vista um aumento de descuido para com a natureza elevando o risco de degradação ambiental.

A educação ambiental vinculada a educação social inserida desde a idade escolar primaria propõe que a Educação Ambiental seja um processo de formação criativo, permanente e participativo, no qual as pessoas envolvidas passem a ser agentes transformadores, participando ativamente da busca de alternativas para a redução de impactos ambientais e para o controle social do uso dos recursos naturais.

No cenário atual a educação ambiental mostra-se significativamente como um novo olhar panorâmico quanto ao crescimento dos movimentos ambientalistas e do interesse principalmente para conservação ambiental e está intimamente ligado à degradação do meio ambiente, aos impactos ambientais e implicando-se na qualidade de vida e na própria natureza da espécie humana.

A partir da Conferência Intergovernamental sobre Educação Ambiental realizada em Tsibilisi (EUA), em 1977, dar início a um amplo processo em nível global orientado para instituir as condições que formem uma nova consciência sobre o valor da natureza e para reorientar a produção de conhecimento bas eada nos métodos da interdisciplinaridade e nos princípios da complexidade. Que permiti a realização de experiências concretas de educação ambiental de forma criativa e inovadora por diversos segmentos da população e em diversos níveis de formação.

Considerando que o campo da educação ambiental ainda está buscando as bases epistemológicas, a sua constituição mais sólida ampara-se também nas interpretações científicas [6].

As investigações e as áreas tidas como tradicionais dos cientistas da educação parecem desconhecer a emergência de uma nova perspectiva denominada de educação ambiental. Nesta ótica inovadora se refere à compreensão de sujeitos a partir da investigação e à integração entre os atores sociais que propõem uma nova maneira de interação (interdisciplinando) entre currículo e as questões ambientais [7].

As questões ambientais se manifestam em nível local seja na escola ou comunidade pretende-se desenvolver nos alunos que os causadores e vítimas estão intrínsecos e fazem parte dos problemas ambientais. A Educação Ambiental (AE) apresenta-se como uma das ferramentas existentes para a sensibilização, conscientização e conservação para o meio ambiente. Que consiste em articular a sociedade civil para as contribuições dos atores sociais na construção dos direitos e de um futuro para o meio ambiente[7].

\section{II.2 PERCEPÇÃO AMBIENTAL}

A percepção está direcionada com o desenvolvimento dos nossos sentidos, que exige que o indivíduo participe desse processo. Por outro lado, o professor deverá propiciar uma atividade perceptiva para que o aluno fortaleça e se exercite dentro do ambiente es colar. Por meio de atividades que permitam ao aluno a comunicação e o desenvolvimento da percepção com relação a si mesmo e ao mundo que o rodeia Dentro deste contexto compreende-se a percepção como "Uma atividade, um estender-se para o mundo. Os órgãos dos sentidos são poucos eficazes quando não são ativamente usados"[8].

A necessidade de comunicação da criança desenvolve-se paralelamente à organização da sua capacidade de percepção e interação do indivíduo como meio através dos órgãos dos sentidos baseada no conhecimento cultural, ético, social e na postura de cada um. De modo que o aluno tenha ópticas perceptivas diferentes sobre um mesmo objeto.

No âmbito escolar a percepção vincula-se de forma em que a criança percebe e adquiri novos conhecimentos no ambiente escolar, conhecimentos es ses que será aplicado posteriormente na vida adulta, onde os principais atores deste processo atuamatravés de relacionamento entre professor versus aluno, aluno versus professor e aluno versus aluno na qual torna-se relevante, uma vez que é a partir disto que a criança irá aprimora-se para a vida em sociedade. Compete ao papel do professor não só mediar o conhecimento, mas vincular o processo de ensino e aprendizagem para o enfrentamento de um ser capaz de resolver por meio da criticidade e formulação pensamentos próprios conforme a sua subjetividade.

Para tanto a Educação Ambiental é uma ferramenta facilitadora para as discussões em relação ao à compreensão, à percepção e à conexão do homem com o meio ambiente. Inserida no contexto escolar a Educação Ambiental onde deve ser abordada e explorada de forma interdisciplinar, possibilitando ao discente o contato constante com o meio ambiente. O contato contínuo e direto desperta nos alunos uma percepção automática da sua 
relação com o meio ambiente e isto facilita a compreensão da importância na preservação e nas atitudes comportamentais do dia a dia [9].

Entretanto nem sempre o conhecimento do problema ambiental é condição para a mudança de valores em benefício à conservação ambiental, é necessário que as atitudes sejam lembradas e exemplificadas diariamente, é preciso sentimento e conhecimento para sensibilizar tanto na forma individual quanto na forma grupal. Por isso ações mitigadoras, projetos criativos e atitudes que despertem o interesse dos alunos são essenciais na aplicação de uma efetiva educação ambiental [9].

\section{II.3 PRÁTICAS PEDAGÓGICAS INTERDISCIPLINANDO COM A EDUCAÇÃO AMBIENTAL}

A educação escolar é umsistema de instrução e ensino de objetivos intencionais, sistematizados e com alto grau de organização, dando a relevância a uma democratização maior dos conhecimentos. E as práticas educativas podem determinar as ações da escola e seu comprometimento social com a transformação para cidadania [10].

Compreender a Educação Ambiental por meio da pratica pedagógica no âmbito escolar apresentam-se dissociados de seu real conceito, acabando por dificultar ao aluno a aquisição de conhecimentos relativos ao exercício das práticas ambientais.

De modo que as práticas pedagógicas relacionadas ao meio ambiente, assimcomo a desempenho do professor necessitam ser revisadas, em decorrência de constantes mudanças principalmente e utilizando-se de estratégias em suas práticas pedagógicas que tem como objetivo propor uma aprendizagem significante. Há necessidade de uma articulação coma produção de sentidos sobre a educação ambiental dentro de um contexto marcado pela degradação permanente do meio ambiente e seu ecossistema, por meio das práticas pedagógicas para reflexão sobre as práticas sociais.

A dimensão ambiental configurava-se como um crescente conjunto de atores do universo educativo, potencializando o engajamento dos diversos sistemas de conhecimentos, a capacitação de profissionais e a comunidade universitária numa perspectiva interdisciplinar e de multiprofissionais [5].

No que concerne a interdiscipliridade compreende-se como um processo de ensino se caracteriza pela combinação de atividades do professore dos alunos, onde compete ao professoro direcionamento do estudo das disciplinas e assim, desta forma os alunos atingem progressivamente o desenvolvimento de suas capacidades mentais [10].

Para tanto, compreende-se que as estratégias de ensino são ações didático pedagógicas intencionais utilizadas para que se possa obter melhores resultados no processo ensino-aprendizado e envolvem as relações professor-aluno; aluno-aluno e alunoconsigo mesmo, imprescindíveis para o desenvolvimento cognitivo para aprender e ensinar. A interação professor e aluno em sala de aula são carregadas de significados e valores, de intencionalidades, de subjetividades próprias de cada olhar, refletindo e garantindo no processo ensino-aprendizado um olhar especial às estratégias de ensino, que ao nosso ver, é o "pano de fundo" que envolve todo o enredo, no qual contracenam os atores da Educação [11].

Nesse sentido, a produção de conhecimento deve necessariamente contemplar as inter-relações do meio natural com o social, incluindo a análise dos determinantes do processo, o papel dos diversos atores envolvidos e as formas de organização social que aumentam o poder das ações alternativas de um novo desenvolvimento, numa perspectiva que priorize novo perfil de desenvolvimento, com ênfase na sustentabilidade socioambiental [5].

Desde modo a interdisciplinaridade apresenta-se como um esforço cognitivo de vinculação entre os componentes curriculares para alcançar objetivos comuns.

A interdisciplinaridade é sempre um processo de diálogo entre disciplinas firmemente estabelecidas em sua identidade teórica e metodológica, mas conscientes de seus limites e do caráter parcial do recorte da realidade sobre o qual operam. Is so implica, por parte dos pesquis adores, res peitar o saber produzido por outras disciplinas, recusando qualquer hierarquia a priori entre elas [...]. [12].

Dentro deste contexto à prática interdisciplinar entre várias disciplinas não supõe uma negação das bases epistemológicas das disciplinas, [...]. A prática da interdisciplinaridade supõe o equilíbrio de dois aspectos, por um lado, uma visão integradora de diversas disciplinas e, por outro, um salto cognitivo que não esteja pressuposto em qualquer somatória de abordagens disciplinares [11].

Interdisciplinaridade desenvolve um trabalho de integração dos conteúdos de uma disciplina que contribui significativamente para o aprendizado. Para tanto a interação entre disciplinas aparentemente distintas é uma maneira complementar ou suplementar que possibilita a formulação de um saber críticoreflexivo, saber esse que deve ser valorizado cada vez no processo de ensino-aprendizado, proporcionando um diálogo entre estas, relacionando-as entre si para a compreensão da realidade. Onde busca-se relacionar as disciplinas no momento de enfrentar temas de estudo de forma reflexiva.

Desta forma, o desenvolvimento da produção do conhecimento deve necessariamente contemplar as inter-relações do meio natural com o social e econômico. E que razão da maior parte da população brasileira viver nas cidades observa-se uma crescente degradação das condições de vida refletindo uma crise ambiental, is to remete a uma necessária reflexão sobre os desafios para mudar as formas de pensar e agir em torno da questão ambiental numa perspectiva contemporânea.

A complexidade ambiental abre uma estimulante oportunidade para compreender a gestação de novos atores sociais que se mobilizam para a apropriação da natureza, para umprocesso educativo articulado e compromissado, mas questiona valores e premissas que norteiam as práticas sociais prevalecentes, implicando mudança na forma de pensar e transformação no conhecimento e nas práticas pedagógicas. O questionamento quanto a reflexão ambiental por meio da percepção apresenta-se como uma estratégia que vem minimizar, fortalecer por meio da educação uma educação ambiental articulada com práticas pedagógica.

Dentro deste contexto a educação ambiental assume cada vez mais a função transformadora por meio da educação com o exercício para a cidadania com a possibilidade de sensibilizar, conscientizar para transformar as diversas formas de participação na defesa da qualidade de à educação ambiental através de seus atores, práticas pedagógicas.

\section{II.4 DESMATAMENTO E QUEIMADAS}

O desmatamento no território brasileiro deu-se início no litoral com a destruição da Mata Atlântica no Nordeste, primeiramente para a extração do Pau-Brasil enviado a Europa para ser usado como madeira e tintura. O processo de degradação da 
cobertura vegetal acelerou-se com a introdução da cultura da canade-açúcar e, posteriormente, com a criação do gado bovino. Da Mata Atlântica no Nordeste, as frentes de desmatamento dirigiramse para o sudeste e suldo país encontrando as Matas de Araucárias e a partir de 1980 para o Centro Oeste avançando sobre os Cerrados por meio da expansão da fronteira em grande parte na borda sul da floresta Amazônica [13].

O desmatamento e as queimadas são considerados umdos grandes problemas ecológicos enfrentados pelo país na atualidade. O Brasil apresenta uma das maiores diversidade biológica com destaque possui em sua fauna e flora, e a falta de um direcionamento no que se refere à sensibilização conscientização e conservação ecológica quanto à exploração dos recursos ambientais vem acarretando prejuízos irreparáveis ao meio ambiente.

O desmatamento e as queimadas não são considerados um impacto ambiental isolado. Estão intimamente ligados a outros danos ecossistêmicos, como a poluição, extinção de animais, aquecimento global e a urbanização e as sentamento de populações (principalmente as ocupações ilegais - invasão), o desenvolvimento da agricultura, a primeira medida tomada é o desmatamento da área, que ocorre sem critérios mínimos de importância ecológica, dos tempos mais remotos até os atuais, em seguida os restos da vegetação não aproveitados são queimados para limpeza da área para a agricultura [13].

Compreende-se por desmatamento, também chamado de desflorestamento ou deflorestação, o processo de remoção totalou parcial da vegetação em uma determinada área. Geralmente, esse processo ocorre para fins econômicos, visando à utilização comercial da madeira das árvores e também para o aproveitamento dos solos para a agricultura e a pecuária. A atividade mineradora e a construção de barragens para hidrelétricas também aparecem como causas de tal ocorrência [14].

Diante da problemática ambiental ocasionada pelo desmatamento e queimadas suas consequências são:

$>\mathrm{O}$ esgotamento dos solos com a intensificação de processos de erosão e desertificação;

$>$ A extinção ou degradação de rios e lagos, graças ao maior acúmulo de sedimentos gerados;

$>$ A ocorrência de desequilíbrios climáticos em razão da ausência das florestas que tinham como função gerar mais umidade do ar e absorver o calor atmos férico;

$>$ A conversão de terra em terreno urbanizado (ou de invasão ocupação ilegal), e uso para a agricultura ou para a pecuária e a criação de infra estruturas como pontes, estradas e barragens;

> O uso da agropecuária, a plantação de soja e criação de gado bovino a exploração madeireira, a grilagem de terras;

$>$ A exploração madeireira principalmente pela procura de madeira para construção, marcenaria ou para uso combustível.

A degradação ambiental está intrinsecamente atrelada à vida cotidiana e os aspectos ambientais abordados são os mais visíveis e os mais recorrentes no dia a dia da população; capazes de serempercebidos pelo próprio ser humano, por is so o comportamento humano deve ser compreendido para que a população humana modifique-o em relação ao espaço ao qual estão inseridos.

\section{II.5 PERCEPÇÃO AMBIENTAL ATRAVÉS DE DESENHOS}

A percepção no meio ambiente em sua completude traz uma análise reflexiva aos indivíduos que permanece em constante desenvolvimento.

Desta forma, por meio das palestras com abordagem de práticas pedagógicas de conscientização, sensibilização, e conservação ao combate na redução dos índices de desmatamento e queimadas, as relações entre indivíduos a partir da sua habitação, escola, áreas verdes e nos ambientes geográficos, no qual o aluno está inserido consolidam-se para um aprendizado significativo.

A ação de desenhar potencializa a criatividade construindo novos conceitos da vida cotidiana representadas pelo simples ato de desenhar.

O desenho é um importante meio de comunicação e representação da criança e apresenta-se como uma atividade fundamental, pois a partir dele a criança expressa e reflete suas idéias, sentimentos, percepções e descobertas. Para a criança o desenho é muito importante, é seu mundo, é sua forma de transformá-lo, é seu meio de comunicação mais precioso [15].

Nesse contexto os alunos conseguemtranscrever por meio do desenho suas expressividades através de seus anseios, suas vontades, seus sentimentos, carências e suas projeções para o cuidado com o meio ambiente.

Observa-se que há uma interação na criatividade entre tudo o que está ao seu entorno, criando um sistema de representação muito rico e de extrema relevância para o processo de aprendizagem. Desse modo, o desenho passa ser uma interpretação que cria relações e constrói códigos e recodifica paradigmas para construção de novos conceitos.

\section{MATERIAIS E MÉTODOS}

Quanto aos procedimentos para aplicação do projeto no primeiro momento realizou-se palestra expositiva, dialogada e contextualizada com temáticas relacionada à relevância da conscientização e conservação Educação Ambiental e ao combate a redução dos índices de queimadas.

No segundo momento Palestra expositivas e dialogadas e contextualizadas de Conscientização e Prevenção e Controle de queimadas e solicitação de mudas aos alunos para distribuição junto à comunidade e construção de cartazes para exposição sobre combate e redução dos índices de queimadas e conscientização para o cuidado com o meio ambiente efetivados em sala de aula para exposição durante a caminhada na comunidade ao entorno da escola.

No terceiro momento apresentação de vídeos referentes a Prevenção e Controle de queimadas. Organização e cuidado na caminhada que será des envolvida coma comunidade no entorno da escola e distribuição de mudas aos alunos e para entregarem aos comunitários do entorno da escola. No quarto momento foi realizado um oficina de desenho livres relacionados ao meios ambiente, onde os alunos expressaram através das criações ilustrativas sobre a percepção ambiental adquirida. No quinto momento realização da caminhada junto com os alunos para exposição dos cartazes de cunho ambiental e entrega de mudas aos comunitários e principalmente um diálogo sobre a sensibilização no combate e redução dos índices de queimadas e de conscientização e conservação ambiental na comunidade no 
entorno da escola, visando integrar a comunidade mobilizando os mesmo sobre a importância do projeto.

Quantos aos recursos necessários foram utilizados:

$>$ Humanos: Professores, Alunos, Funcionários e Comunidade.

$>$ Materiais: Serão utilizados Livros Didáticos, e Paradidáticos, Quadro Branco, lápis, canetas, pinceis hidrocor, Computador, Data-show, Papelaria (cartolina), Revistas, Jornais, CD's / DVD's.

$>$ Realização da atividade sempre na coletividade e efetivação quanto à mediação da atividade desenvolvida com intuito de despertar a conscientização no combate e redução dos índices de queimadas. O profess or sendo o mediador escriba.

\section{RESULTADOS E DISCUSSÕES}

A seguir serão mostrados os resultados obtidos com a implementação do projeto Uma Reflexão Interdisciplinar sobre a Percepção da Educação Ambiental nas Práticas Pedagógicas do Ensino Fundamental I

A figura 1 mostra as palestras sendo realizadas na Escola.

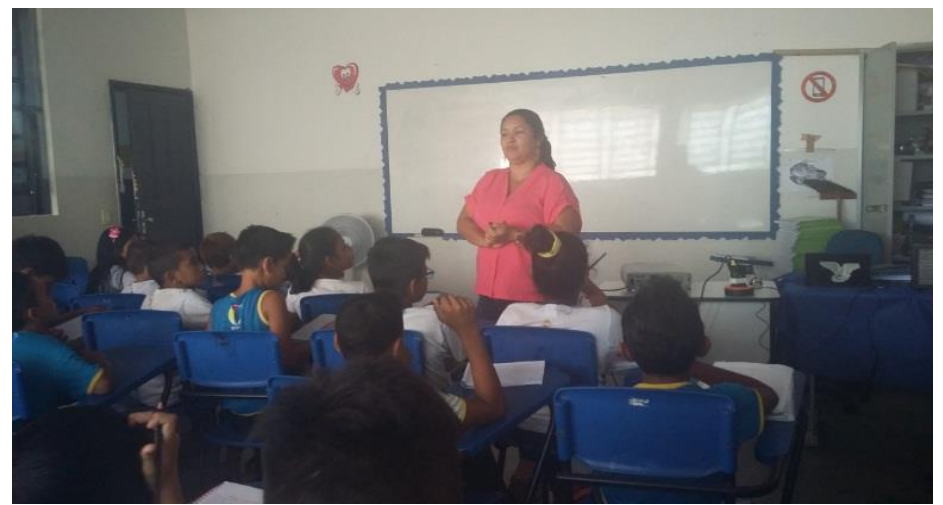

Figura 1: Palestra sobre Conscientização e Prevenção e Controle de queimadas.

Fonte: Autores, (2017).

A figura 2 mostra a participação dos alunos do 5 ano do Ensino Fundamental I, nas atividades juntamente com a palestrante do projeto.

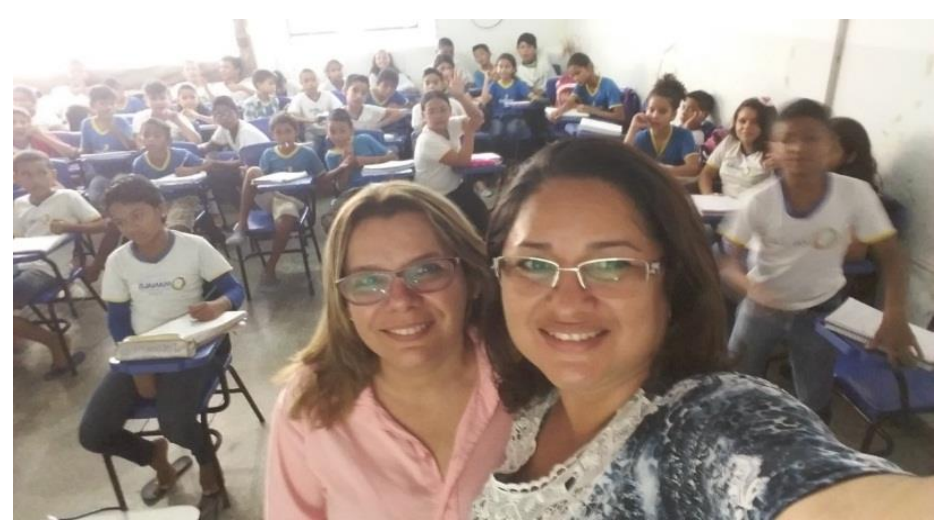

Figura 2: Participação das turma do 5 ano nas Palestras.

Fonte: Autores, (2017).
Após as palestras foram realizadas atividades descontraídas onde os alunos criaram através de desenhos que representavam no momento a percepção ambiental sobre o aprendizado. A criança, por meio do desenho, interage com o meio ambiente, de acordo com [15]: $O$ desenho constitui para a criança uma atividade total, englobando o conjunto de suas potencialidades. Ao desenhar, a criança expressa a maneira pela qual se sente existir. O desenvolvimento do potencial criativo na criança seja qual for o tipo de atividade em que ela se expresse, é essencial ao ciclo inato de crescimento. Similarmente, as condições para o seu pleno crescimento (emocional, psíquico, físico, cognitivo) não podem ser estáticas.

O desenho está intrínseco no desenvolvimento das crianças esse ato traz uma expressividade pela qual a criança desenvolve seu potencial de criatividade. A criança ao desenhar a representatividade perceptiva está comprometida com a criatividade na ação de desenhar, onde propiciam através das representações significados percebidos no imaginário para reflexão sobre os novos conceitos.

A figura 3 mostra a participação dos alunos em um momento de descontração emque os mesmos estavamexpressando através da criação de desenhos relacionado a percepção ambiental no entendimento da turma, após as palestra realizadas.

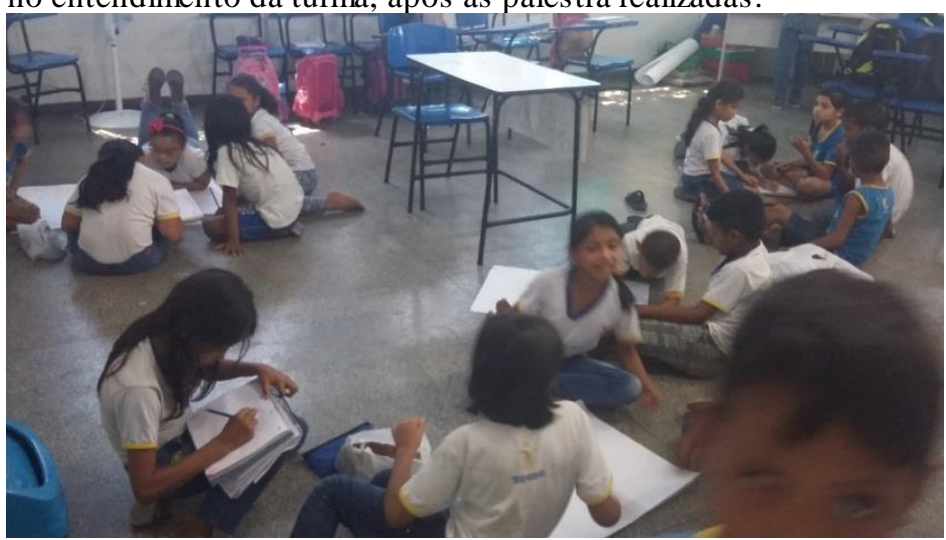

Figura 3: Construção de desenhos sobre percepção ambiental.

Fonte: Autores, (2017).

Desenhos de Percepção ambienta criado da pelos alunos da turma $5^{\circ}$ Ano do Ensino Fundamental I. O desenho da Figura 4, realizado por uma aluna de 10 anos de idade com necessidades educacionais especiais (Autismo) é um exemplo de desenho que trans mite uma compreensão de destruição da natureza causada pelo desmatamento e queimadas e como há expressividade do sofrimento da própria natureza.

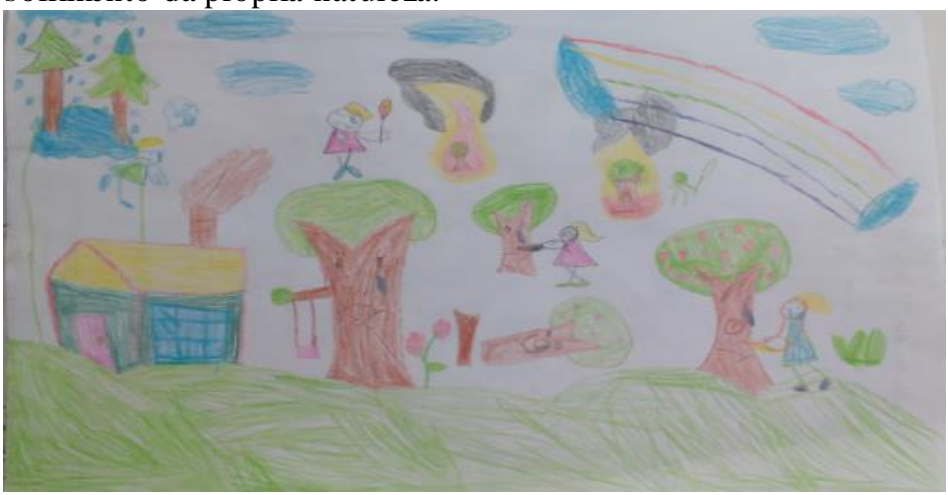

Figura 4: Percepção Ambiental sobre o Desmatamento e Queimadas na visão de uma aluna do $5^{\circ}$ ano do Ensino Fundamental I com necessidades educacionais especiais -Autis mo. Fonte: Autores, (2017). 
O desenho da Figura 5, realizado por um aluno com 12 anos de idade. Percebe-se que o mesmo desenvolveu um aumento da sensibilidade quanto à de destruição perceptiva ao meio ambiente com cunho comercial (extração de madeira) a partir da palestra.

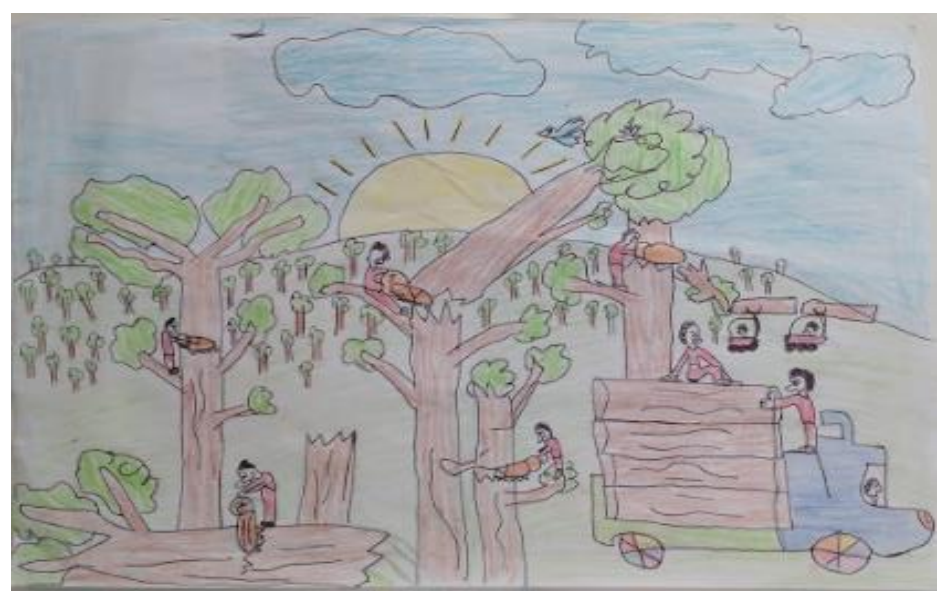

Figura 5: Percepção ambiental na visão de um aluno do ensino Fundamental I de 12 anos, mostra a extração madeireira comercial ilegal.

Fonte: Autores, (2017).

O desenho da Figura 6 realizado por um aluno com 12 anos de idade. Percebe-se que o mesmo desenvolveu um aumento da sensibilidade quanto à de destruição perceptiva ao meio ambiente no que concerne à fauna (representatividade de um animal morto e outro tentando fugir) e flora (onde as labaredas estão destruindo intensamente as árvores por meio das queimadas), outro ponto relevante observado são as emissões de gases na atmosfera, a partir da palestra.

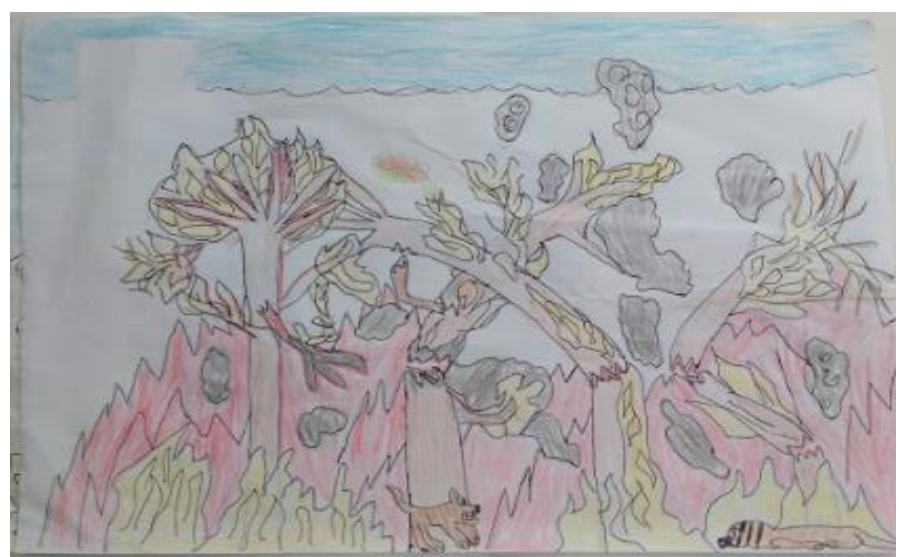

Figura 6: Percepção ambiental na visão de umaluno do ensino Fundamental I de 12 anos, mostra a destruição da fauna e flora. Fonte: Autores, (2017).

Realizou-se uma exposição com os desenhos criados pelos alunos para a comunidade escolar. Essa exposição estimulou a todos a se unir contra a destruição ambiental.

Para isso, foram confeccionados cartazes pelos alunos para mobilização na comunidade aos arredores da escola para a importância da conservação e preservação do meio ambiente para a humanidade.

A figura 7 mostra os alunos da turma do ensino fundamental I, confeccionando os cartazes para a caminhada junto à comunidade.

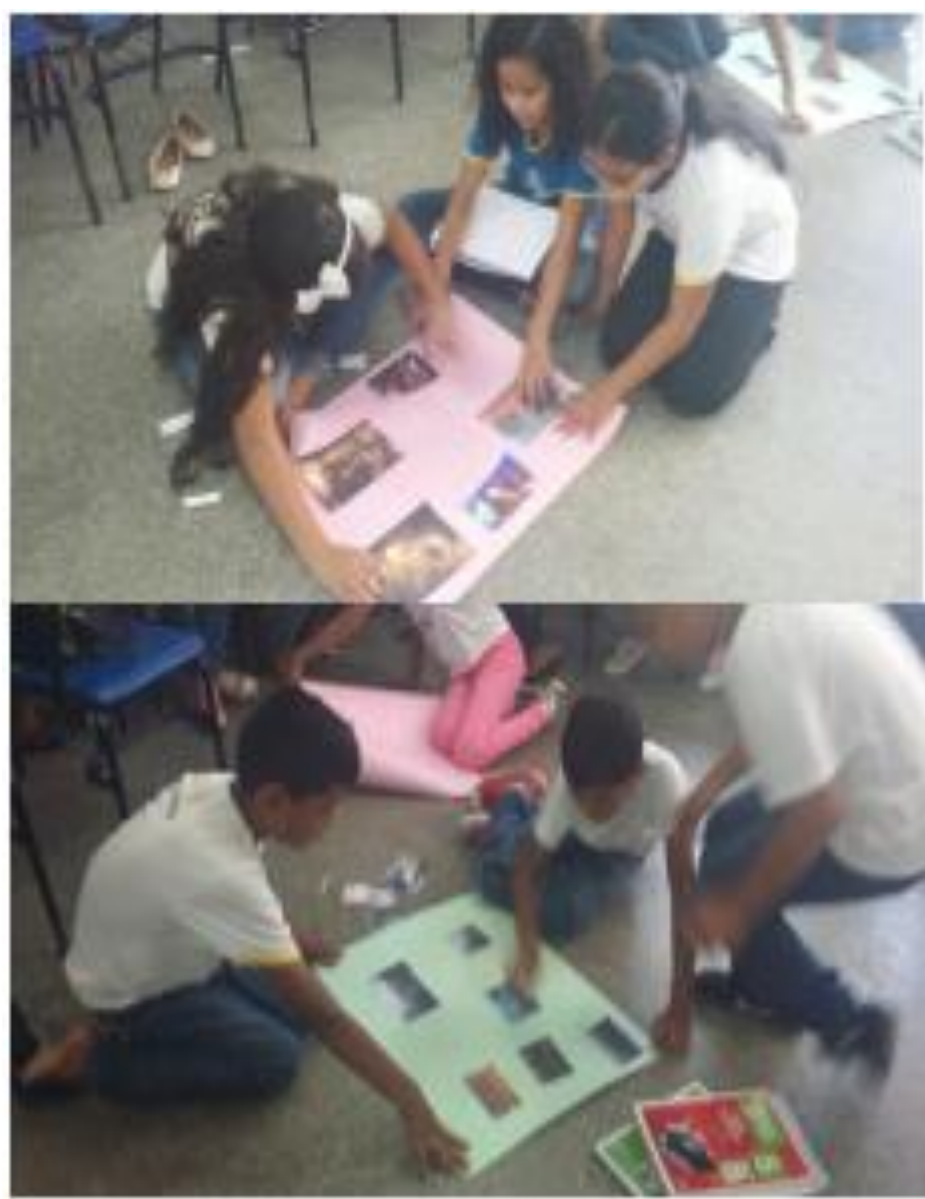

Figura 7: Construção de cartazes para realização da caminha na comunidade no entorno da escola sobre a relevância da Conscientização e Conservação do Meio Ambiente.

Fonte: Autores, (2017).

Desempenhado um papel de aprendizado renovador contra a destruição do meio ambiente emfunção das queimadas, os alunos distribuíram mudas de árvores frutíferas para serem plantadas junto à comunidade do entrono da escola. A figura 08 mostra a caminhada de mobilização.

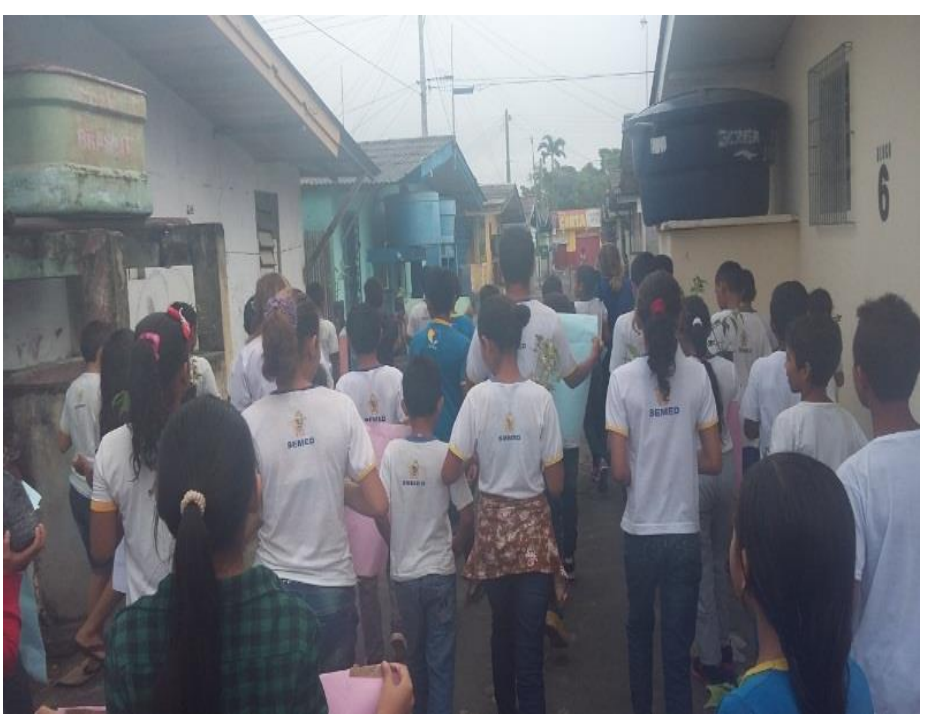

Figura 8: Caminhada de mobilização junto à comunidade no entorno da escola.

Fonte: Autores, (2017). 
A figura 9 ilustra os alunos distribuindo as mudas junto à comunidade.

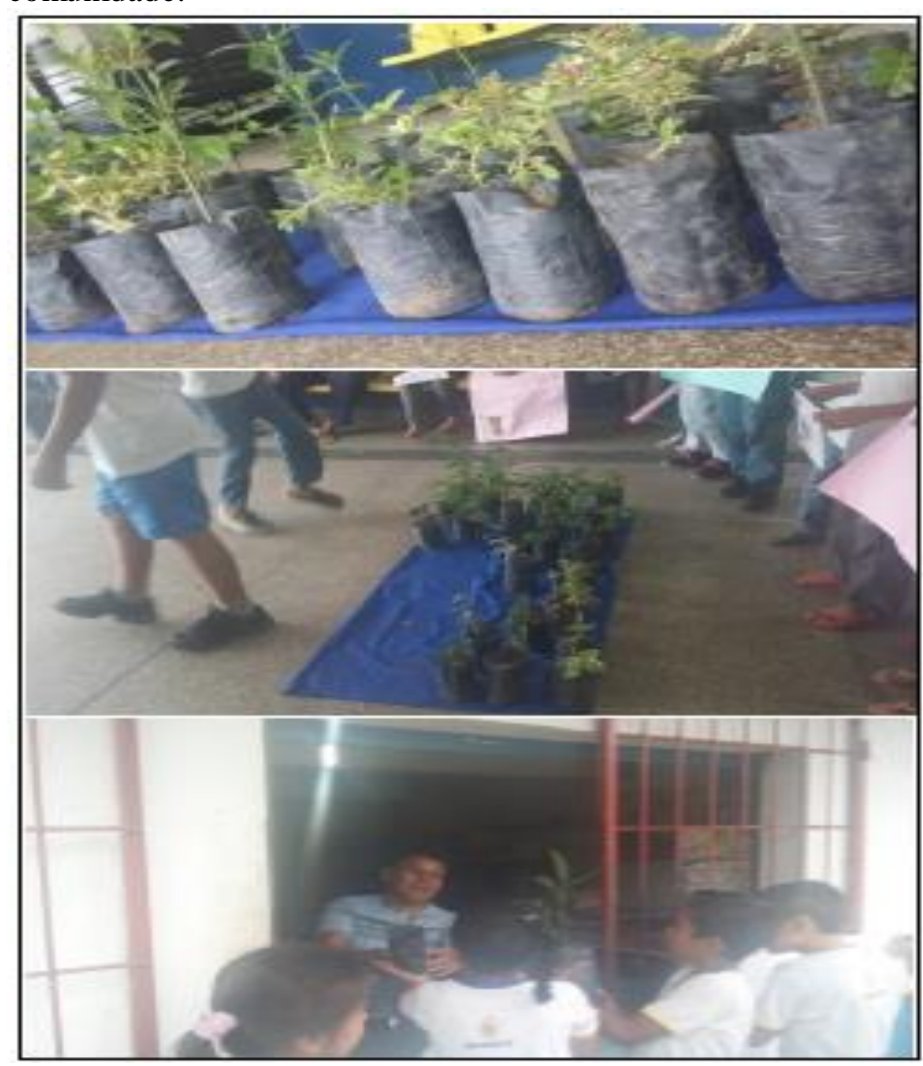

Figura 9: Distribuição de Mudas .

Fonte: Autores, (2017).

\section{CONCLUSÃO}

A partir desse contexto as práticas pedagógicas, formais ou não-formais, desempenham a singularidade dos sujeitos quanto sua construção enquanto cidadãos capazes de participar de tomadas de decisão em reconhecer os problemas socioambientais atuais para os quais busca-se soluções individuais ou coletivas para o desenvolvimento humano na construção da cidadania por meio de uma sensível percepção dos ambientes na qual os sujeitos esta inseridos.

Quanto aos Resultados obtidos com a pesquisa sugere-se adesão no calendário pedagógico para sua efetivação utilizando-se das práticas pedagógicas de ensino voltadas a Educação Ambiental que contemple principalmente alunos e comunidade, para um despertar crítico e consciente de modo formal e não-formal visando a relevância da educação ambiental para transformação social

\section{AGRADECIMENTOS}

Ao Programa de Pós-Graduação de Mestrado Profissional em Ciências e Meio Ambiente (PGCMA) do Instituto de Ciências Naturais da Universidade Federal do Pará (UFPA) e ao Instituto de Tecnologia e Educação Galileo da Amazônia (ITEGAM) pelo apoio a pesquisa.

\section{REFERÊNCIAS}

[1] Adams, B. G. A importância da Lei 9.795/99 e das diretrizes curriculares nacionais da Educação Ambiental para docentes. Monografias Ambientais, v. 10, n. 10, p. 2148-2157, 2013.
[2] Civil, P. D. R.-C. Política Nacional de Educação AmbientalLei 9795/99. 1999.

[3] Oliveira, A. L. D.; Obara, A. T.; Rodrigues, M. A. Educação ambiental: concepções e práticas de professores de ciências do ensino fundamental. Revista Eectrónica de Enseñanza de las Ciencias, v. 6, n. 3, p. 471-495, 2007.

[4] MARCATTO, C. Educação ambiental: conceitos e princípios. Belo Horizonte: FEAM, v. 1, 2002.

[5] Jacobi, P. Educação ambiental, cidadania e sustentabilidade. Cadernos de pesquisa, v. 118, n. 3, p. 189-205, 2003.

[6] De Andrade, L. M. Educação ambiental crítica: breves considerações conceituais, metodológicas e institucionais. Semioses, v. 10, n. 2, p. 13-28, 2016.

[7] Guimarães, M. Educação ambiental crítica. Identidades da educação ambiental brasileira. Brasília: Ministério do Meio Ambiente, p. 25-34, 2004.

[8] Gonçalves, A. A.; Lima, M. E. O.; Marques, M. R. A percepção e educação ambiental com alunos do ensino fundamental. 2009.

[9] Barbosa, L. A. S. Educação Ambiental e Linguagem: o uso do livro paradidático interativo como proposta pedagógica para despertar a sensibilização ambiental. 2014.

[10] Barcellos, S. B. Ações em Educação Ambiental e suas Relações com a Interdisciplinaridade e Cidadania: o caso do projeto social "Educação Ambiental na Vila Kennedy”. 2009.

[11] Okane, E. S. H.; Takahashi, R. T. O estudo dirigido como estratégia de ensino na educação profissional em enfermagem. Revista da Escola de Enfermagem da USP, v. 40, n. 2, p. 160-169, 2006.

[12] LEIS, H. R. Especificidades e desafios da interdisciplinaridade nas ciências humanas. PHILIPPI Jr, A.; NETO, AJS (ed). Interdisciplinaridade em ciência, tecnologia e inovação. Barueri: Manole, p. 106-122, 2011.

[13] Machado, C. A. Desmatamentos e queimadas na região norte do estado do tocantins. Caminhos de Geografia, v. 13, n. 43, 2012.

[14] Alvarenga, A. D. et al. Histórico, fundamentos filosóficos e teórico-metodológicos da interdisciplinaridade. Interdisciplinaridade em ciência, tecnologia e inovação. Barueri: Manole, p. 3-68, 2011.

[15] Goldberg, L. G.; Yunes, M. A. M.; Freitas, J. D. O desenho infantil na ótica da ecologia do desenvolvimento humano. Psicologia em estudo, v. 10, n. 1, p. 97-106, 2005. 